\title{
Produtividade do maracujazeiro amarelo sob diferentes níveis de irrigação e doses de potássio via fertirrigação(1)
}

\author{
Valdemício Ferreira de Sousa(2), Marcos Vinícius Folegatti(3), José Antônio Frizzone ${ }^{(3)}$ \\ Rodrigo Alessandro de Lima Corrêa ${ }^{(3)}$ e Waleska Martins Eloi(4)
}

\begin{abstract}
Resumo - O objetivo deste trabalho foi avaliar o efeito de quatro níveis de irrigação e cinco doses de $\mathrm{K}$ aplicadas via fertirrigação por gotejamento na produtividade do maracujazeiro amarelo (Passiflora edulis Sims f. flavicarpa Deg.). O delineamento experimental usado foi o de blocos ao acaso em parcelas subdivididas com quatro repetições. Os níveis de irrigação (subparcelas) aplicados foram os seguintes: $0,25 \mathrm{~V}(926,76 \mathrm{~L}) ; 0,50 \mathrm{~V}(1.528,20 \mathrm{~L}) ; 0,75 \mathrm{~V}(2.117,28 \mathrm{~L}) ; 1,00 \mathrm{~V}(2.706,36 \mathrm{~L})$, em que $\mathrm{V}$ é o volume médio de água aplicado em lisímetro contendo uma planta de maracujá. As doses de K aplicadas em kg de $\mathrm{K}_{2} \mathrm{O}$ por planta por ano foram: 0,$000 ; 0,225 ; 0,450 ; 0,675$ e 0,900 . A produtividade comercial do maracujazeiro foi influenciada significativamente $(\mathrm{P}<0,01)$ pelas doses de $\mathrm{K}$, pelos níveis de irrigação e pela interação doses de $\mathrm{K}$ e níveis de irrigação. Os maiores valores de produtividade comercial do maracujazeiro amarelo foram obtidos com a aplicação de doses de $\mathrm{K}$ e níveis de água variando de 0,450 a $0,675 \mathrm{~kg}_{\text {planta }}{ }^{-1}$ ano $^{-1}$ de $\mathrm{K}_{2} \mathrm{O}$ e de $1.528,20$ a $2.117,28 \mathrm{~L}_{\text {planta }}{ }^{-1}$ ano $^{-1}$, respectivamente.
\end{abstract}

Termos para indexação: Passiflora edulis, manejo da água, aplicação de fertilizante, irrigação por gotejamento.

\section{Yield of passion fruit under different irrigation levels and potassium doses by fertirrigation}

Abstract - The objective of this work was to study the effect of four irrigation levels and five K doses applied through fertirrigation by drip irrigation system in the yellow passion fruit (Passiflora edulis Sims f. flavicarpa Deg.) yield. A complete randomized block design in plot subdivided with four replications was used. The treatments resulted from the combination of four irrigation levels $[0.25 \mathrm{~V}(926.76 \mathrm{~L})$, $0.50 \mathrm{~V}(1,528.20 \mathrm{~L}), 0.75 \mathrm{~V}(2,117.28 \mathrm{~L})$ and $1.00 \mathrm{~V}(2,706.36 \mathrm{~L})$, where $\mathrm{V}$ is the average volume of water applied in lysimeter with passion fruit plant] with five $\mathrm{K}$ doses $(0.000,0.225,0.450,0.675$ and $0.900 \mathrm{~kg}$ plant $^{-1}$ year ${ }^{-1}$ of $\mathrm{K}_{2} \mathrm{O}$ ). The commercial yield was affected by irrigation levels, $\mathrm{K}$ doses and by the interaction irrigation levels vs. $\mathrm{K}$ doses. The majors values of passion fruit commercial yield were obtained with the application of 0.450 to $0.675 \mathrm{~kg} \mathrm{plant}^{-1}$ year $^{-1}$ of $\mathrm{K}_{2} \mathrm{O}$, and water levels of 1,528.20 to 2,117.28 $\mathrm{L} \mathrm{plant}^{-1}$ year ${ }^{-1}$, respectively.

Index terms: Passiflora edulis, water management, fertilizer application, trickle irrigation.

(1) Aceito para publicação em 8 de janeiro de 2003 Extraído da tese de doutorado apresentada pelo primeiro autor à Escola Superior de Agricultura Luiz de Queiroz (Esalq), Piracicaba, SP

(2) Embrapa-Centro de Pesquisa Agropecuária do Meio-Norte, Caixa Postal 01, CEP 64006-220 Teresina, PI E-mail: vfsousa@cpamn.embrapa.br

(3) Esalq, Dep. de Engenharia Rural, Caixa Postal 9, CEP 13418-900 Piracicaba, SP. E-mail mvfolega@carpa.ciagri.usp.br, frizzone@carpa.ciagri.usp.br, ralcorre@carpa.ciagri.usp.br

(4) Universidade Federal do Ceará, Dep. de Engenharia Agrícola, Av. da Universidade, 2853, Benfica, CEP 60020-181 Fortaleza, CE. Bolsista da Funcap. E-mail: waleskaeloi@msn.com

\section{Introdução}

O maracujazeiro amarelo (Passiflora edulis Sims f. flavicarpa Deg.) é uma frutífera bastante cultivada no Brasil e de bom retorno econômico para os produtores. Com área plantada de 33.012 ha, o Brasil é o principal produtor mundial de maracujá (Maracujá, 2000). Apesar dessa posição, a produtividade nacional é muito variada e, na maioria das vezes, baixa em relação ao potencial produtivo da cultura.

A produtividade do maracujazeiro é muito afetada pela radiação solar, temperatura e número de ho- 
ras de brilho solar. Fatores como estresse hídrico e deficiências nutricionais, associados a dias curtos e baixas temperaturas do ar e do solo, restringem o crescimento e o potencial produtivo do maracujazeiro (Simon \& Karnatz, 1983; Menzel et al., 1986).

Os ciclos alternados de vegetação e de produção apresentados pelo maracujazeiro amarelo exigem ótimo estado nutricional das plantas em todas as fases do processo produtivo, pois há grande demanda por energia na planta e forte drenagem de nutrientes das folhas para os frutos em desenvolvimento, reduzindo a intensidade vegetativa da planta (Menzel et al., 1993), requerendo, assim, um esquema de adubação que permita a manutenção da cultura em estado nutricional adequado.

Além do estado nutricional, a irrigação no maracujazeiro promove ótimo desenvolvimento das plantas, aumenta a produtividade e permite a obtenção de produção de forma contínua e uniforme, com frutos de boa qualidade. A irrigação por gotejamento é a mais adequada para a cultura, no entanto, segundo Ruggiero et al. (1996), independentemente do método ou sistema de irrigação utilizado, cuidados devem ser tomados para não permitir que as plantas sejam submetidas a estresse hídrico e nem a excesso de umidade.

A utilização adequada da água em cultivos irrigados tem condicionado aos produtores a garantia da produção; todavia, a maximização da produtividade não se dá apenas com o fornecimento de água às culturas. A elevação do nível de fertilidade do meio é também importante para o desenvolvimento e produção das plantas (Sousa et al., 2002).

A forma tradicional de aplicação de fertilizantes nas culturas irrigadas vem sendo substituída pela fertirrigação, ou seja, aplicação de fertilizantes simultaneamente com a água de irrigação. A irrigação por gotejamento tem-se mostrado bastante eficiente no cultivo de fruteiras, uma vez que a água e os fertilizantes são aplicados pontualmente, na zona de concentração das raízes (Phene et al., 1979).

O efeito da adubação na produtividade do maracujazeiro é relatado por vários autores (Müller et al., 1979; Colauto et al., 1986; Martins, 1998; Carvalho et al., 2000). Todavia, a literatura quase não traz referências sobre os efeitos da combinação de fertilizantes e água de irrigação, principalmente em regime de fertirrigação. No Brasil, foram desenvolvidos vários trabalhos sobre as exigências nutricionais do maracujazeiro (Haag et al., 1973; Baumgartner et al., 1978; Müller et al., 1979; Souza et al., 1979; Faria et al., 1991). Contudo, na maioria deles, as produtividades situamse abaixo de $10 \mathrm{t} \mathrm{ha}^{-1}$, inferiores às registradas por Martins (1998) e Carvalho et al. (1999) de 35,28 tha-1 e 34,60 t ha-1, respectivamente, provavelmente porque nestes dois trabalhos os autores utilizaram novas técnicas de manejo da cultura, principalmente adubação e irrigação.

O K é o elemento de maior mobilidade na planta, e passa com facilidade de uma célula para outra e do xilema para o floema. Por isso, é o componente mineral de maior expressão nos processos osmóticos que envolvem absorção e armazenamento de água pelas plantas (Ruggiero et al., 1996). O K é requerido em grande quantidade pelas plantas e tem papel fundamental na translocação de assimilados para as diversas partes da planta, principalmente para os frutos, influenciando o rendimento e a qualidade do produto colhido (Daliparthy et al., 1994). A deficiência de K no maracujazeiro provoca redução na ramificação, no comprimento e no diâmetro dos ramos, atraso na floração, redução no tamanho dos frutos e área foliar, afetando, conseqüentemente, a fotossíntese e o conteúdo de sólidos solúveis nos frutos (Ruggiero et al., 1996; Quaggio \& Piza Júnior, 1998).

O objetivo deste trabalho foi avaliar o efeito de quatro níveis de irrigação e cinco doses de K aplicadas via fertirrigação por gotejamento na produtividade do maracujazeiro amarelo.

\section{Material e Métodos}

O experimento foi realizado de março/1999 a junho/2000, no Campo Experimental da Fazenda Areão da Escola Superior de Agricultura Luiz de Queiroz (USP), em Piracicaba, SP (22०42'30" S; 47038'0" W). Para a caracterização física e química do solo foram retiradas amostras nas camadas de $0,00-0,20 \mathrm{~m}, 0,20-0,40 \mathrm{~m}$ e $0,40-0,60 \mathrm{~m}$ (Tabelas 1 e 2). A Tabela 3 apresenta as médias mensais de temperatura do ar, umidade relativa do ar, precipitação pluvial e média diária da evapotranspiração de referência (Penman-Monteith) do período de maio/1999 a abril/2000.

O preparo do solo consistiu de duas gradagens, com posterior aplicação e incorporação de $2,0 \mathrm{t} \mathrm{ha-1}$ de calcário dolomítico, 60 dias antes do transplantio das mudas, para 
Tabela 1. Caracterização química do solo da área experimental ${ }^{(1)}$.

\begin{tabular}{cccccccccc}
\hline $\begin{array}{c}\text { Camada } \\
(\mathrm{m})\end{array}$ & $\begin{array}{c}\mathrm{pH} \\
\left(\mathrm{CaCl}_{2}\right)\end{array}$ & $\begin{array}{c}\mathrm{MO} \\
\left(\mathrm{g} \mathrm{dm}^{-3}\right)\end{array}$ & $\begin{array}{c}\mathrm{P} \\
\left(\mathrm{mg} \mathrm{dm}^{-3}\right)\end{array}$ & $\begin{array}{c}\mathrm{K} \\
-------\end{array}\left(\mathrm{mmol}_{\mathrm{c}} \mathrm{dm}^{-3}\right)$ & $\mathrm{H}+\mathrm{Al}$ & $\mathrm{T}$ & $\mathrm{V}$ \\
\hline $0,00-0,20$ & 5,20 & 14 & 4 & 1,50 & 33 & 13 & 28 & 75,50 & 63 \\
$0,20-0,40$ & 5,00 & 17 & 4 & 1,60 & 28 & 12 & 31 & 72,60 & 57 \\
$0,40-0,60$ & 5,30 & 9 & 6 & 0,50 & 32 & 6 & 22 & 60,50 & 64 \\
\hline
\end{tabular}

${ }^{(1)} \mathrm{MO}$ : matéria orgânica; T: capacidade de troca de cátions; V: saturação por bases.

Tabela 2. Caracterização física do solo da área experimental ${ }^{(1)}$.

\begin{tabular}{ccccccc}
\hline $\begin{array}{c}\text { Camada } \\
(\mathrm{m})\end{array}$ & \multicolumn{1}{c}{ CC } & PMP & $\begin{array}{c}\rho s \\
\left(\mathrm{~kg} \mathrm{dm}^{-3}\right)\end{array}$ & $\begin{array}{c}\text { Argila } \\
-\cdots\end{array}$ & $\begin{array}{c}\text { Silte } \\
\left(\mathrm{g} \mathrm{kg}^{-1}\right)\end{array}$ \\
\hline $0,00-0,20$ & 0,4148 & 0,3472 & 1,49 & 624,0 & 172,0 & 204,0 \\
$0,20-0,40$ & 0,4193 & 0,3491 & 1,46 & 694,3 & 138,3 & 167,4 \\
$0,40-0,60$ & 0,4500 & 0,3808 & 1,43 & 688,9 & 136,4 & 174,8 \\
\hline
\end{tabular}

${ }^{(1)} \mathrm{CC}$ : capacidade de campo; PMP: ponto de murcha permanente; $\rho \mathrm{s}$ : densidade do solo.

Tabela 3. Valores médios mensais de temperatura $(\mathrm{T})$, umidade relativa (UR), precipitação pluvial (P) e média diária da evapotranspiração de referência (ETo) no período de maio/1999 a abril/2000.

\begin{tabular}{lccrc}
\hline Meses & $\begin{array}{c}\mathrm{T} \\
\left({ }^{\circ} \mathrm{C}\right)\end{array}$ & $\begin{array}{c}\text { UR } \\
(\%)\end{array}$ & \multicolumn{1}{c}{$\begin{array}{c}\mathrm{P} \\
(\mathrm{mm})\end{array}$} & $\begin{array}{c}\mathrm{ETo}^{(1)} \\
\left(\mathrm{mm} \mathrm{dia}^{-1}\right)\end{array}$ \\
\hline Maio & 18,30 & 79 & 51,30 & 2,06 \\
Junho & 17,50 & 83 & 68,60 & 1,76 \\
Julho & 19,20 & 77 & 2,70 & 2,11 \\
Agosto & 19,10 & 64 & 0,00 & 2,87 \\
Setembro & 21,40 & 70 & 85,90 & 3,82 \\
Outubro & 21,90 & 73 & 28,50 & 4,43 \\
Novembro & 22,60 & 72 & 52,10 & 4,01 \\
Dezembro & 24,80 & 78 & 269,90 & 4,77 \\
Janeiro & 24,70 & 83 & 235,90 & 3,77 \\
Fevereiro & 24,60 & 87 & 195,00 & 3,62 \\
Março & 24,10 & 84 & 170,00 & 3,20 \\
Abril & 21,90 & 72 & 0,00 & 2,91 \\
\hline
\end{tabular}

(1)Estimada pelo método Penman-Monteith.

elevação da saturação de bases a $80 \%$. As covas foram abertas no espaçamento de $3,5 \times 4,0 \mathrm{~m}$, com formato cilíndrico, com $1,0 \mathrm{~m}$ de diâmetro e $0,5 \mathrm{~m}$ de profundidade. A adubação de fundação foi feita conforme Meletti \& Maia (1999), aplicando por cova: $40 \mathrm{~L}$ de esterco de curral, $0,20 \mathrm{~kg}$ de $\mathrm{P}_{2} \mathrm{O}_{5}$ (superfosfato simples), 0,004 kg de $\mathrm{Zn}$ (sulfato de zinco) e $0,001 \mathrm{~kg}$ de B (ácido bórico). As mudas de maracujazeiro amarelo (Passiflora edulis Sims f. flavicarpa Deg.) foram plantadas com 35 dias de idade.

O sistema de irrigação utilizado foi gotejamento, com gotejadores autocompensantes, em linha com vazões diferenciadas $\left(2,4 \mathrm{~L} \mathrm{~h}^{-1} \mathrm{e} 4,0 \mathrm{~L} \mathrm{~h}^{-1}\right)$, os quais foram distribuídos em quantidade variada por planta para permitir a casualização dos níveis de irrigação por tratamento.
Os gotejadores foram dispostos em círculo, com distância média de $0,40 \mathrm{~m}$ do caule da planta.

A quantidade de água aplicada foi definida de acordo com o balanço médio de entrada e saída de água em lisímetros de drenagem, com superfície circular de $1,23 \mathrm{~m}^{2}$ e profundidade de $1,5 \mathrm{~m}$, instalados no centro da área experimental; considerando a precipitação efetiva e a eficiência do sistema de irrigação. Para a determinação da lâmina de máxima irrigação, utilizaram-se as equações 1 e 2:

$\mathrm{V}=\mathrm{n}_{\mathrm{g}} \mathrm{qTi} / \mathrm{E}_{\mathrm{f}}$,

$\mathrm{L}=\mathrm{V} / \mathrm{A}_{\mathrm{l}}$,

em que: $\mathrm{V}$ é o volume de água aplicado em cada lisímetro (L); $\mathrm{n}_{\mathrm{g}}$ é o número de gotejadores no lisímetro; q é a vazão do gotejador $\left(\mathrm{L} \mathrm{h}^{-1}\right)$; Ti é o tempo de irrigação (h); $\mathrm{E}_{\mathrm{f}}$ é a eficiência de irrigação $(0,90)$; Lé a lâmina máxima de irrigação $(\mathrm{mm}) ; \mathrm{A}_{1}$ é a área do lisímetro $\left(\mathrm{m}^{2}\right)$.

O momento da irrigação foi definido tomando-se por base o potencial matricial, entre $-8,5$ e $-10 \mathrm{kPa}$, medido nos tensiômetros instalados nos lisímetros. O monitoramento da umidade no solo foi feito por intermédio de tensiômetros instalados a $0,30 \mathrm{~m}$ do caule da planta, nas profundidades de $0,10,0,30,0,50$ e $0,70 \mathrm{~m}$.

Utilizou-se o delineamento experimental de blocos ao acaso com parcelas subdivididas, e quatro repetições. Os tratamentos foram constituídos por quatro níveis de irrigação (subparcelas) e cinco doses de K (parcelas). Cada unidade experimental, com área de $56 \mathrm{~m}^{2}$, foi constituída por duas plantas úteis e duas de bordadura. Os níveis de irrigação foram: $\mathrm{L}_{1}=0,25 \mathrm{~V}(926,76 \mathrm{~L}) ; \mathrm{L}_{2}=0,50 \mathrm{~V}$ $(1.528,20 \mathrm{~L}) ; \mathrm{L}_{3}=0,75 \mathrm{~V}(2.117,28 \mathrm{~L}) ; \mathrm{L}_{4}=1,00 \mathrm{~V}$ $(2.706,36 \mathrm{~L})$. Em cada lisímetro e nas plantas das subparcelas do tratamento $\mathrm{L}_{4}$ foram colocados cinco gotejadores com vazão de $4 \mathrm{~L} \mathrm{~h}^{-1}$. As doses de $\mathrm{K}$ aplicadas 
em kg de $\mathrm{K}_{2} \mathrm{O}$ por planta por ano foram: $\mathrm{K}_{0}=0,000$; $\mathrm{K}_{1}=0,225 ; \mathrm{K}_{2}=0,450 ; \mathrm{K}_{3}=0,675$ e $\mathrm{K}_{4}=0,900$. Foram utilizados o cloreto de potássio na fase de formação e o nitrato de potássio na fase de produção.

A adubação com $\mathrm{N}$ foi definida com base nas recomendações de Meletti \& Maia (1999) e feita por meio da água de irrigação, na freqüência de aplicação de sete dias. Aplicaram-se nas fases de formação e de produção $0,10 \mathrm{~kg}$ de $\mathrm{N}$ e $0,38 \mathrm{~kg}$ de $\mathrm{N}$ por planta, respectivamente.

$\mathrm{Na}$ fase de formação, a distribuição dos nutrientes ao longo do ciclo da cultura foi feita de forma linear, em 15 aplicações. Durante a fase de produção, a aplicação dos nutrientes foi feita em 32 vezes, conforme a marcha de absorção (Tabela 4).

A colheita foi realizada de janeiro a junho/2000, com intervalo médio de três dias. Os frutos foram colhidos quando atingiram o ponto de maturação, ou seja, em torno de $14^{\circ}$ Brix. Consideraram-se frutos comerciais aqueles com peso acima de $45 \mathrm{~g}$ e não danificados. Utilizou-se o Programa Estatístico SANEST na análise de variância e de regressão dos dados obtidos.

\section{Resultados e Discussão}

A produtividade comercial do maracujazeiro foi influenciada significativamente $(\mathrm{P}<0,01)$ pelas doses de $\mathrm{K}(\mathrm{CV}=8,39 \%)$, pelos níveis de irrigação $(\mathrm{CV}=11,26 \%)$ e pela interação desses fatores. A análise de regressão mostrou que a aplicação de diferentes lâminas de irrigação na ausência de adubação com $\mathrm{K}\left(\mathrm{K}_{0}\right)$ promoveu efeito linear crescente, com ajuste significativo $(\mathrm{P}<0,05)$ (Figura 1$)$. Isso evidencia que nesse tipo de solo, sem adubação potássica, existe uma ligeira tendência de crescimento da produtividade comercial do maracujazeiro

Tabela 4. Valores porcentuais de acúmulo de $\mathrm{N}$ e de $\mathrm{K}$ pelo maracujazeiro na fase de produção( ${ }^{(1)}$.

\begin{tabular}{ccc}
\hline $\begin{array}{c}\text { Períodos } \\
\text { (dias) }\end{array}$ & $\begin{array}{c}\mathrm{N} \\
(\%)\end{array}$ & $\begin{array}{c}\mathrm{K} \\
(\%)\end{array}$ \\
\hline $130-160$ & 5,0 & 4,5 \\
$160-190$ & 5,7 & 4,8 \\
$190-220$ & 6,0 & 5,7 \\
$220-250$ & 7,3 & 6,3 \\
$250-280$ & 10,0 & 10,2 \\
$280-310$ & 17,0 & 17,5 \\
$310-340$ & 22,0 & 23,0 \\
$340-370$ & 27,0 & 28,0 \\
\hline
\end{tabular}

(1) Adaptado de Haag et al. (1973). amarelo, com o aumento de níveis de água aplicados por gotejamento.

Esse comportamento pode ser explicado pelo movimento e transporte de $\mathrm{K}^{+}$das regiões próximas do sistema radicular para a zona de absorção das raízes, favorecida pela diferença de concentração deste íon (Malavolta, 1981), provocada pela intensa absorção pelas raízes e teores mais elevados de umidade, uma vez que o teor de $\mathrm{K}$ da área experimental, na camada de 0,00-0,20 m, antes do plantio, era de $1,5 \mathrm{mmol}_{\mathrm{c}} \mathrm{dm}^{-3}$ de $\mathrm{K}$, considerado médio (Raij, 1991). A diagnose foliar nesse tratamento apresentou concentração de $\mathrm{K}$ entre 12,24 e $14,15 \mathrm{~g} \mathrm{~kg}^{-1}$, teores abaixo dos encontrados por Haag et al. (1973) e Menzel et al. (1993), entre 20 e $30 \mathrm{~g} \mathrm{~kg}^{-1}$ de K e 23 e $32 \mathrm{~g} \mathrm{~kg}^{-1}$ de $\mathrm{K}$, respectivamente.

As interações lâminas de irrigação com as doses de $\mathrm{K}$ revelaram efeitos quadráticos (Figura 1). As máximas produtividades do maracujazeiro foram obtidas com a aplicação de 1.932,84, 1.825,00, 1.868,55 e 1.613,21 L planta-1 ano $^{-1}$, combinados com as doses $\mathrm{K}_{1}, \mathrm{~K}_{2}, \mathrm{~K}_{3}$ e $\mathrm{K}_{4}$, respectivamente, evidenciando que maiores rendimentos de frutos comerciais do maracujazeiro amarelo são obtidos com níveis intermediários de irrigação, entre $1.528,20 \mathrm{~L}$ e 2.117,28 L, como observado por Martins (1998) e Carvalho et al. (1999, 2000), que constataram efeitos quadráticos de lâminas de irrigação sobre a produtividade do maracujazeiro amarelo.

O comportamento dos modelos quadráticos mostra uma tendência na obtenção de pontos de máxima com a aplicação da maior e menor quantidades de água, quando combinadas com menores e maiores doses de $\mathrm{K}$, respectivamente. Para $\mathrm{K}_{1}$ e $\mathrm{K}_{4}$ as máximas produtividades foram obtidas com a aplicação de $1.932,84$ e 1.616,21 L planta $^{-1}$ ano $^{-1}$, respectivamente. Essa tendência pode ser atribuída aos efeitos da dinâmica do K no solo, influenciada tanto pela difusão como pelo fluxo de massa (Malavolta, 1981; Raij, 1991). Assim, o aumento nos teores de água no solo associado à maior dose de $\mathrm{K}$ pode ter provocado mais transportes de $\mathrm{K}^{+}$para fora da zona radicular, afetando a produção de frutos, ao passo que menores doses de $\mathrm{K}$, associadas a teores mais elevados de água no solo, podem ter promovido melhor distribuição de $\mathrm{K}^{+}$na zona de concentração radicular. Martins (1998) obteve a máxima produtividade do 

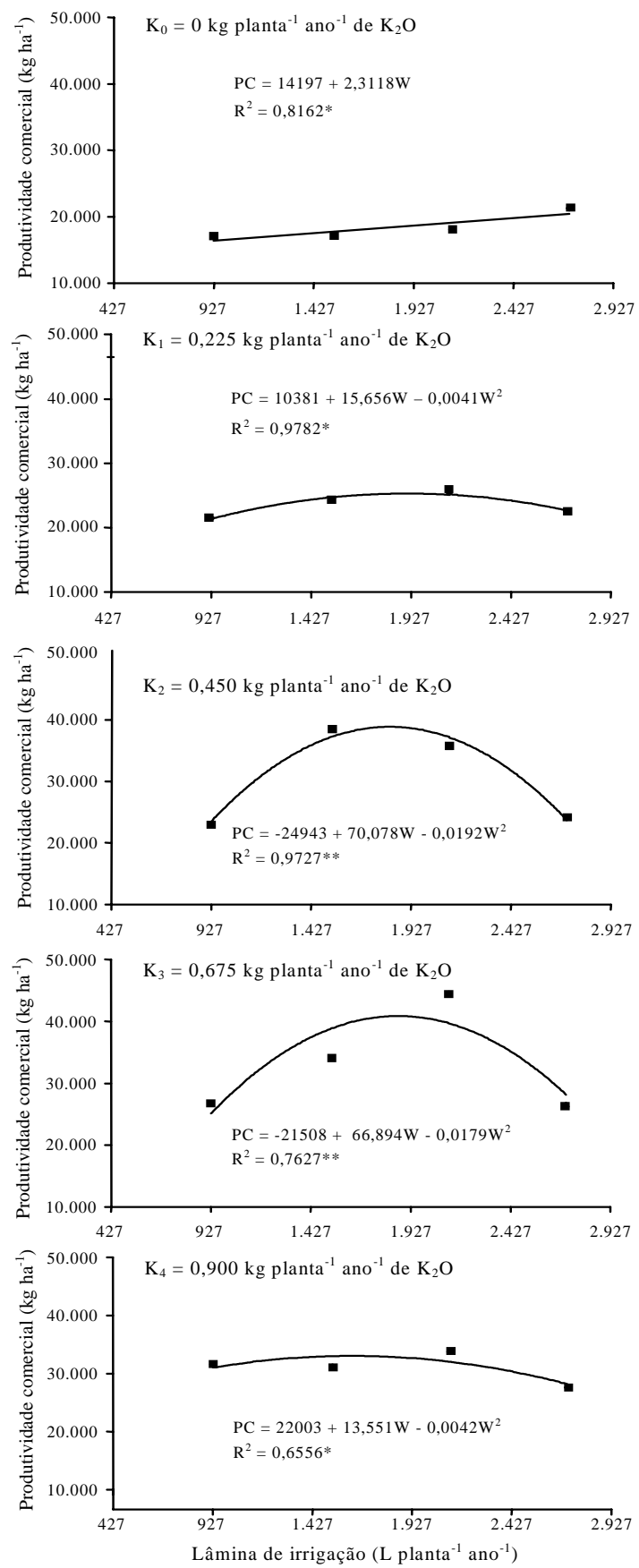

Figura 1. Efeitos da interação entre lâmina de irrigação (W) e doses de potássio aplicadas por fertirrigação na produtividade comercial (PC) do maracujazeiro amarelo. * e **Significativo a $5 \%$ e a $1 \%$ de probabilidade, respectivamente. maracujazeiro (35.280 $\left.\mathrm{kg} \mathrm{ha}^{-1}\right)$ com a lâmina de água de $1.454 \mathrm{~mm}$, o que diverge deste trabalho, cuja máxima produtividade $\left(40.989,47 \mathrm{~kg} \mathrm{ha}^{-1}\right)$ foi obtida com a aplicação de 1.868,55 L planta ${ }^{-1}$ ano $^{-1}$ (944,22 mm). Isto se deve, provavelmente, às diferentes condições ambientais onde foram realizados os experimentos e à inclusão da precipitação no valor da lâmina considerada por Martins (1998).

A análise de regressão da interação de doses de $\mathrm{K}$ com os níveis de irrigação na produtividade comercial do maracujazeiro revelou que com os níveis de irrigação $\mathrm{L}_{1}\left(\mathrm{R}^{2}=0,9757^{* *}\right)$ e $\mathrm{L}_{4}\left(\mathrm{R}^{2}=0,9893^{*}\right)$, houve crescimento linear da produtividade comercial com o aumento das doses de K; já com os níveis de irrigação $L_{2}$ e $L_{3}$, as doses de $\mathrm{K}$ favoreceram o crescimento da produtividade comercial com o aumento das doses até a aplicação de 0,602 e $0,662 \mathrm{~kg}$ planta $^{-1} \mathrm{de} \mathrm{K}_{2} \mathrm{O}$, respectivamente (Figura 2). A partir daí, as produtividades tenderam a decrescer. Nesses dois casos, as doses de K que determinaram os pontos de máximo foram muito próximas.

$\mathrm{Na}$ adubação do maracujazeiro as pesquisas têm evidenciado a importância prática do balanço $\mathrm{N}: \mathrm{K}$ (Carvalho et al., 1999), cuja relação deve estar em torno de 1:2 (Haag et al., 1973; Paula et al., 1974). Neste trabalho, esta relação não proporcionou as maiores produtividades, pois como foi aplicado $0,48 \mathrm{~kg}$ planta $^{-1}$ ano $^{-1}$ de N, somente a dose $\mathrm{K}_{4}$ esteve mais próxima de atender à relação de $1: 2$; evidenciando que o fator água no solo pode alterar esta tendência, visto que, com o nível de irrigação $\mathrm{L}_{4}$, a variação da produtividade decorrente do aumento de K aplicado não foi tão expressiva quando comparado com $\mathrm{L}_{2}$ e $\mathrm{L}_{3}$.

Os maiores teores de $\mathrm{K}$ nas folhas $(22,22,4 \mathrm{e}$ $23 \mathrm{~g} \mathrm{~kg}^{-1}$ ) foram registrados com as combinações $\mathrm{L}_{2} \mathrm{~K}_{2}, \mathrm{~L}_{2} \mathrm{~K}_{3}$ e $\mathrm{L}_{3} \mathrm{~K}_{3}$, respectivamente, os quais estão de acordo com as faixas encontradas por Haag et al. (1973) e Menzel et al. (1993).

Os níveis de irrigação $\mathrm{L}_{2}$ e $\mathrm{L}_{3}$ foram os que mais favoreceram a produtividade comercial. Essas quantidades de água aplicadas, além de manterem níveis ótimos de umidade para a cultura, podem ter permitido maior disponibilidade de nutrientes. Essas condições provavelmente contribuíram para elevar a disponibilidade de $\mathrm{K}$ no solo, à medida que se aumentaram as doses de $\mathrm{K}_{2} \mathrm{O}$, inibindo a absorção de outros 

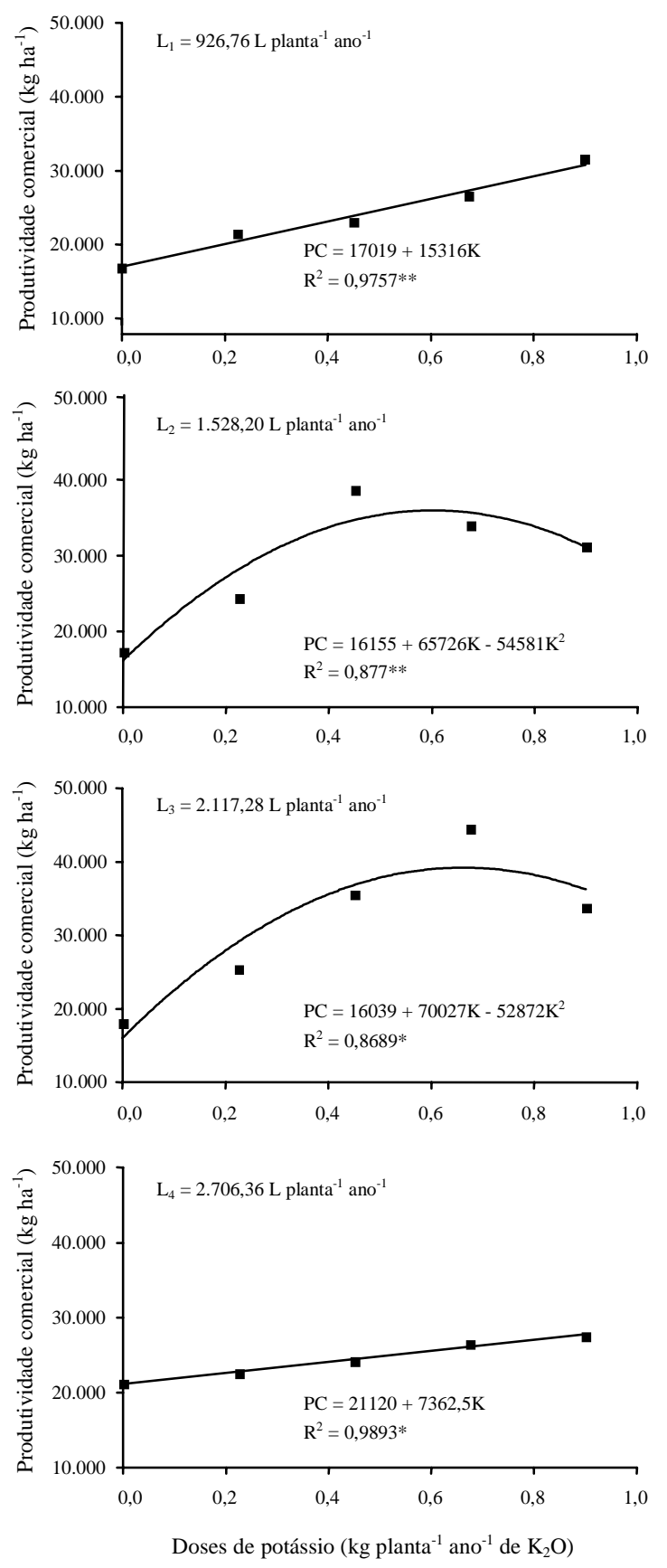

Figura 2. Efeitos da interação entre doses de potássio (K) aplicados por fertirrigação e lâminas de irrigação na produtividade comercial (PC) do maracujazeiro amarelo. * e **Significativo a $5 \%$ e a $1 \%$ de probabilidade, respectivamente. elementos essenciais à produção do maracujazeiro amarelo, principalmente $\mathrm{Ca}$ e $\mathrm{Mg}$, que em altas concentrações no solo reduzem a absorção de $\mathrm{K}^{+}$ (Malavolta, 1981), cujo efeito antagônico também ocorre especialmente em fruteiras (Epstein, 1975) e no maracujazeiro amarelo (Primavesi \& Malavolta, 1980).

O comportamento verificado em $\mathrm{L}_{2}$ e $\mathrm{L}_{3}$ está de acordo com Martins (1998), que constatou efeitos quadráticos, com redução da produtividade ao aumentar as doses de $\mathrm{K}$ a partir de $0,448 \mathrm{~kg}_{\text {planta }}{ }^{-1} \mathrm{ano}^{-1}$. As produtividades comerciais obtidas neste trabalho foram superiores à média nacional $\left(9,21 \mathrm{t} \mathrm{ha}^{-1}\right)$, à média no Estado de São Paulo (16,90 t ha-1) (Maracujá, 2000) e aos resultados encontrados por Faria et al. (1991) (14,80 tha-1). Entretanto, foram próximas às obtidas por Martins (1998) $\left(35,28 \mathrm{t} \mathrm{ha}^{-1}\right) \mathrm{e}$ Carvalho et al. (2000) (entre 36,80 e 41,30 t ha-1).

O peso médio de frutos do maracujazeiro não foi influenciado pelos níveis de irrigação, doses de K e interação. As variações entre os valores de peso médio de frutos foram baixas, com CV de 5,84\% e 7,7\%, considerando as doses de $\mathrm{K}$ e os níveis de irrigação, respectivamente.

O menor valor (131,45 g) e o maior valor $(144,31 \mathrm{~g})$ de peso médio de frutos foram obtidos com $\mathrm{K}_{0}$ e $\mathrm{K}_{4}$, respectivamente. Considerando os níveis de irrigação, a mesma tendência não foi verificada, pois os valores médios foram de 136,98 g e 138,44 g nos níveis $\mathrm{L}_{4}$ e $\mathrm{L}_{2}$, respectivamente, mostrando um acréscimo no peso médio de frutos até a aplicação de $\mathrm{L}_{2}$, reduzindo ligeiramente em seguida.

Martins (1998) verificou variação no peso médio de frutos de $108 \mathrm{~g}$ a $151 \mathrm{~g}$, porém foi influenciado significativamente apenas pelas lâminas de irrigação, concordando estatisticamente com os resultados deste trabalho, apenas para o efeito das doses de K; contudo, foram divergentes de Müller et al. (1979), cujos valores de peso médio de frutos foram influenciados pelas doses de potássio. Ainda com relação aos efeitos de lâminas de irrigação no peso médio de frutos do maracujazeiro amarelo, este trabalho também diverge de Carvalho et al. (2000), que obtiveram frutos com peso médio entre $147 \mathrm{~g}$ e $161 \mathrm{~g}$, influenciados significativamente pelas diferentes lâminas de irrigação. 


\section{Conclusões}

1. A produtividade comercial do maracujazeiro é influenciada pelas doses de $\mathrm{K}$, pelos níveis de água e pela interação desses fatores.

2. Os maiores valores de produtividade comercial do maracujazeiro amarelo são obtidos com a aplicação de doses de $\mathrm{K}$ e níveis de água variando de 0,450 a $0,675 \mathrm{~kg}_{\text {planta }}{ }^{-1}$ ano $^{-1}$ de $\mathrm{K}_{2} \mathrm{O}$ e de $1.528,20$ a 2.117,28 $\mathrm{L} \mathrm{planta}^{-1} \mathrm{ano}^{-1}$, respectivamente.

\section{Referências}

BAUMGARTNER， J. G.; LOURENÇO, R. S.; MALAVOLTA, E. Estudos sobre nutrição e adubação do maracujazeiro (Passiflora edulis Sims f. flavicarpa Deg.) V: adubação mineral. Científica, Jaboticabal, v. 6, n. 3, p. $361-367,1978$.

CARVALHO, A. J. C. de; MARTINS, D. P.; MONNERAT, P. H.; BERNARDO, S. Adubação nitrogenada e irrigação no maracujazeiro amarelo I: produtividade e qualidade dos frutos. Pesquisa Agropecuária Brasileira, Brasília, v. 35, n. 6, p. 11011108 , jun. 2000.

CARVALHO, A. J. C. de; MARTINS, D. P.; MONNERAT, P. H.; BERNARDO, S. Produtividade e qualidade do maracujazeiro amarelo em resposta à adubação potássica sob lâminas de irrigação. Revista Brasileira de Fruticultura, Jaboticabal, v. 21, n. 3, p. 333-337, dez. 1999.

COLAUTO, N. M.; MANICA, I.; REBOLDI, J.; MIELNICZUK, J. Efeito do nitrogênio, fósforo e potássio, sobre a produção, qualidade e estado nutricional do maracujazeiro amarelo. Pesquisa Agropecuária Brasileira, Brasília, v. 21, n. 7, p. 691-695, jul. 1986.

DALIPARTHY, J.; BARKER, A. V.; MONDAL, S. S Potassium fractions with other nutrients in crops: a review focusing on the tropics. Journal of Plant Nutrition, New York, v. 17, p. 1859-1886, 1994.

EPSTEIN, E. Nutrição mineral de plantas: princípios e perspectivas. Rio de Janeiro: Livros Técnicos e Científicos/EDUSP, 1975. $341 \mathrm{p}$.

FARIA, J. L. C.; COLAUTO, N. M.; MANICA, I.; STRONSKI, M. dos S.; APPEL, H. B. Efecto de tres dosis de N, P y K en la producción de maracayá amarillo (Passiflora edulis Sims f. flavicarpa Deg.) durante tres años de evaluación en Guaíba, Rio Grande do Sul, Brasil. Pesquisa Agropecuária Brasileira, Brasília, v. 26, n. 3, p. 311-314, mar. 1991.

HAAG, H. P.; OLIVEIRA, G. D.; BORDUCHI, A. S.; SARRUGE, J. R. Absorção de nutrientes por duas variedades de maracujá. Anais da Escola Superior de Agricultura Luiz de Queiroz, Piracicaba, v. 30, p. 267-279, 1973.

MALAVOLTA, E. Manual de química agrícola: adubos e adubações. São Paulo: Agronômica Ceres, 1981. $596 \mathrm{p}$.

MARACUJÁ. Agrianual: Anuário Estatístico da Agricultura Brasileira, São Paulo, p. 398-406, 2000.

MARTINS, D. P. Resposta do maracujazeiro amarelo (Passiflora edulis Sims f. flavicarpa Deg.) a lâminas de irrigação e doses de nitrogênio e potássio. 1998. $84 \mathrm{f}$. Tese (Doutorado em Fitotecnia). Universidade Estadual do Norte Fluminense, Campos dos Goytacazes, 1998.

MELETTI, L. M. M.; MAIA, M. L. Maracujá: produção e comercialização. Campinas: Instituto Agronômico, 1999. 26 p. (Boletim Técnico, 181).

MENZEL, C. M.; HAYDON, G. E.; DOODAN, V. J.; SIMPSON, D. R. New standard leaf nutrient concentrations for passion fruit based on seasonal phenology and leaf composition. Journal of Horticultural Science, Cambridge, Inglaterra, v. 68, n. 2, p. 215-230, 1993.

MENZEL, C. M.; SIMPSON, D. R.; DOWLING, A. J. Water relations in passion fruit: effect of moisture stress on growth, flowering and nutrient uptake. Scientia Horticulturae, Amsterdam, v. 29, p. 239-349, 1986.

MÜLLER, C. H.; PINHEIRO, R. V. R.; CASALI, V. W. D.; OLIVEIRA, L. M. de; MANICA, I.; SOUSA, A. C. G. de. Efeitos de doses de sulfato de amônio e de cloreto de potássio sobre a produtividade e sobre a qualidade de maracujás colhidos em épocas diferentes. Revista Ceres, Viçosa, MG, v. 26, n. 143, p. 48-64, 1979.

PAULA, O. F. de; LOURENÇO, R.; MALAVOLTA, E. Estudos sobre a nutrição mineral do maracujazeiro (Passiflora edulis f. flavicarpa) - I: extração de macro e micronutrientes na colheita. Revista de Agricultura, Piracicaba, v. 49, n. 2/3, p. 61-66, nov. 1974.

PHENE, C. J.; FOUSS, J. L.; SANDERS, D. C. Water nutrient herbicide management of potatoes with trickle irrigation. American Potato Journal, Orono, v. 56, p. 51-59, 1979. 
PRIMAVESI, A. C. P. A.; MALAVOLTA, E. Estudos sobre a nutrição mineral do maracujá amarelo - VI: efeitos dos macronutrientes no desenvolvimento e composição mineral das plantas. Anais da Escola Superior de Agricultura Luiz de Queiroz, Piracicaba, v. 37, n. 2, p. 609 $630,1980$.

QUAGGIO, J. A.; PIZA JÚNIOR, C. de T. Nutrição mineral da cultura do maracujá. In: SIMPÓSIO BRASILEIRO SOBRE A CULTURA DO MARACUJÁ, 5., 1998, Jaboticabal. Anais... Jaboticabal: Funep, 1998. p. 130-156.

RAIJ, B. van. Fertilidade do solo e adubação. Piracicaba: Ceres/Potafos, 1991. 343 p.

RUGGIERO, C.; SÃO JOSÉ, A. R.; VOLPE, C. A.; OLIVEIRA, J. C. de; DURIGAN, J. F.; BAUMGARTNER, J. G.; SILVA, J. R. da; NAKAMURA, K.; FERREIRA, M. E.; KVATI, R.; PEREIRA, V. da P. Maracujá para exporta- ção: aspectos técnicos da produção. Brasília: EmbrapaSPI, 1996. 64 p. (Publicações Técnicas FRUPEX, 19)

SIMON, P.; KARNATZ, A. Effect of soil and air temperature on growth and flower formation of purple passion fruit (Passiflora edulis Sims). Acta Horticulturae, Wageningen, v. 139, p. 120-128, 1983.

SOUSA, V. F. de; FOLEGATTI, M. V.; COELHO FILHO, M. A.; FRIZZONE, J. A. Distribuição radicular do maracujazeiro sob diferentes doses de potássio aplicadas por fertirrigação. Engenharia Agrícola e Ambiental, Campina Grande, v. 6, n. 1, p. 51-56, 2002.

SOUZA, E. A.; NOCITI, P. R. H.; FERREIRA, M. E.; RUGGIERO, C.; GRISI, C. Adubação N, P e K em maracujazeiro amarelo (Passiflora edulis Sims f. flavicarpa Deg.). Científica, Jaboticabal, v. 7, p. 727-730, 1979. 